\title{
Gereja Universal Dan Fasilitas Retret Dengan Pendekatan METAFISIKA Di BANDUNGAN
}

\author{
Ginda Chriesma Yoga, Widi Suroto, Hardiyati \\ Program Studi Arsitektur \\ Universitas Sebelas Maret Surakarta \\ Email : gindachriesma@gmail.com
}

\begin{abstract}
This time, in the modern era, human lifestyle are increasingly changing the human habit who makes them more concern with a worldly life and tarnished their needs of God, thus starving of their spirit has been ignored. For some people to go to church only be regarded as a formality or just things that do not even need to do. This makes human have lack understanding about the human essence which are part of God creation. Now, the church only seen as a building which is place to worship, the true meaning from the church is the human itself. This deconstruction of meaning are writer try to reverse back as a basis of Church planning and design. The problem in this design process is how to design church which can make physical and psychological impact to the user. The Universal Church of Metaphysics approach is most suitable appointed because the elements of Metaphysics Architecture can give impact to user psychical and physical. The Universal means intended to accommodate all of the Nazarenes, not only for Christian or Catholic believes, as well as to facilitate all people physical condition, normal people or disabilities people. Metaphysics Architecture can be achieved from some aspects consist of archetype, nature, light, materials, human, and memories which will be creating particular feel and atmosphere in the design. The main target of this architecture form is the user that is human. All of senses and sensors on the human body become essence in this work. Through planning location, nature, and all of architectural details which writer implemented to Universal Church and Retreat Facilities design, which have an aim to restore the human essence and can 'presenting' the God inside of the design.
\end{abstract}

Keywords: Human and God, Metaphysics Phenomenon, Universal Church

\section{PENDAHULUAN}

Tubuh merupakan unsur lahiriah manusia, unsur daging yang dapat dilihat didengar, disentuh. Jiwa adalah unsur batiniah manusia yang tidak dapat dilihat. Unsur dari jiwa meliputi pikiran, emosi, dan kehendak, sedangkan roh adalah prinsip kehidupan manusia. Roh adalah nafas yang dihembuskan Tuhan ke dalam tubuh duniawi dan pada saatnya nanti akan kembali lagi kepada Tuhan, yang merupakan kesatuan spiritual dalam manusia. Roh adalah sifat alami manusia yang 'imaterial' yang memungkinkan manusia berkomunikasi dengan Tuhan, dan salah satu caranya adalah dengan berdoa. Doa merupakan kegiatan yang bersifat rohani dan membutuhkan waktu dan wadah/ruang untuk dapat lepas dari hiru pikuk rutinitas duniawi.

Namun dengan seiring perkembangan zaman dan 'tuntutan lifestyle' khususnya di wilayah perkotaan, kebutuhan fisik duniawi menjadi prioritas utama manusia sehingga mulai memudarkan kebutuhan mereka akan
Tuhan. Kelaparan Roh mereka sendiri sudah tidak diperhatikan. Seharusnya datang ke Gereja merupakan suatu kebutuhan dasar, sekarang menjadi sebatas sebuah 'kewajiban' semata atau bahkan tidak perlu lagi. Bentuk kehidupan seperti inilah yang mulai menghilangkan nilai-nilai dasar manusia sebagai ciptaan Tuhan.

Gereja Universal mewadahi umat nasrani terbatas pada agama Katolik atau pun Kristen. Gereja ini hanya akan memiliki fungsi tunggal, yaitu media penghubung antara manusia dengan Tuhan. Fenomena metafisika biasanya dialami manusia dalam keadaan sadar namun manusia itu sendiri tidak sadar sedang atau telah mengalami abstraksi tersebut. Fenomena ini sebenarnya bisa disadari namun belum tentu dimengerti dengan sensor-sensor yang ada di tubuh manusia.

Seperti pada buku karya Lynda Waggoner (1996) mengenai karya Frank Lloyd Wright yaitu 'Falling Water House', elemen rancangan yang beliau rancang tidak mendasar 
hanya pada bagaimana ruangan masif yang ditata, namun menyeluruh dari di mana lokasi bangunan itu, bentuk kondisi lingkungan yang diintepretasikan ke dalam bentuk fisik bangunan, komunikasi antara bangunan, manusia, lingkungan, hingga detail seperti musik alam dari gemericik air terjun yang menjadi kesatuan dalam karya fenomenal tersebut. Dari pembelajaran tersebut arsitektur dapat mempengaruhi sensor-sensor manusia dan menghasilkan dampak secara fisik maupun psikologis pengguna di dalamnya. Seperti yang diutarakan oleh Mangunwijaya (1988) inti dalam berarsitektur adalah menciptakan suasana, saat seseorang dibawa ke sebuah alam dan waktu yang berbeda dalam sebuah karya arsitektur, hal itulah yang menjadikan karya tersebut fenomenal dan memiliki arti yang mendalam.

Hal inilah yang coba dimanfaatkan penulis di dalam desain gereja, yang bertujuan untuk mengembalikan hakekat manusia dan dapat 'menghadirkan' Tuhan di dalamnya.

\section{METODE}

Dalam proses perancangan proyek ini ada beberapa hal mengenai elemen-elemen arsitektur yang perlu ditekankan agar konsep metafisika yang diterapkan dapat muncul pada tiap aspek perancangan.

Konsep metafisika yang diangkat diambil menurut teori dari Peter Zumthor (1999) yang menjabarkan tentang aspek dalam pernerapan metafisika di dalam bentuk arsitektur yaitu :

\section{Archetype}

Dapat diartikan sebagai pola dasar yang berfungsi sebagai pondasi dalam mengolah bentuk fisik bangunan pada perancangan proyek. Contoh archetype antara lain : gunung, batu, tumbuhan, air.

2. Alam

Kombinasi antara ruang luar dan ruang dalam yang menunjukkan kesatuan antara bentuk-bentuk buatan manusia (arsitektur) dengan bentuk-bentuk alam (elemen lansekap) yang membuat perancangan arsitektur lebih dinamis.

3. Cahaya

Elemen yang sangat penting untuk pengolahan ruang dalam arsitektur karena cahaya dapat mendefinisikan warna dan material yang diterapkankan pada arsitektur. Selain itu cahaya dapat mengolah atmosfer atau suasana yang diinginkan.

4. Material

Material adalah bagian kecil dari alam yang diproses manusia agar dapat diterapkankan pada karya arsitektur dan material itu sendiri dapat terdefinisi karena adanya cahaya. Penerapan material perlu adanya pertimbangan karena elemen ruang luar dan ruang dalam sangat mempengaruhi kondisi psikologis pengguna dalam menerima rangsangan pada perancangan arsitektur.

5. Manusia

Manusia memiliki panca indera yang dapat menerima rangsangan dari sekitarnya. Panca indera inilah yang digunakan sebagai penerapan konsep metafisika. Tiap indera akan diterapkan agar pengguna dapat menerima maksud yang disajikan dalam bentuk-bentuk arsitektur.

6. Memori

Memori adalah bagian dari manusia yang sangat kuat. Kepribadian seseorang dibentuk oleh peristiwa masa lalu dan masa depannya sangat terpengaruh oleh pengalaman di masa lalu. Cara seseorang berpikir didasarkan pada kesalahan masa lalu atau dari pengetahuan yang diperoleh pada sesaat lalu. Dengan demikian, memori dalam pengalaman berarsitektur memainkan peranan yang sangat penting yang berkaitan dengan rangsangan yang saat ini diproduksi oleh lingkungan dengan pengalaman masa lalu, sehingga perasaan atau pikiran ini diproduksi dalam kepala seseorang.

Memori setiap orang pastilah berbeda antara satu dengan yang lain. Namun, pasti ada satu titik ada sebuah pengalaman yang sama pada setiap individunya, seperti pengalaman saat sebelum terjadi hujan ada aroma tanah basah yang terhembus angin, secara spontan akan muncul pikiran sebentar lagi akan turun hujan.

Memori semasa kecil juga dapat ambil bagian dalam perancangan sebuah ide arsitektur, seperti menyusun balok-balok kayu yang kemudian dibuat rumahrumahan atau bentuk tertentu. Kegembiraan saat itu dapat tercermin kembali saat seseorang beranjak dewasa 
dan menemui aktualisasi dalam sebuah karya arsitektur menurut memori masa lampau tersebut.

\section{ANALISIS}

Proyek tugas akhir Gereja Universal dan Fasilitas Retret dengan Pendekatan Metafisika di Bandungan ini berlokasi di area dataran tinggi dan berkontur, untuk itu perbedaan ketinggian tanah dapat digunakan sebagai pemintakatan hierarki penempatan fungsi dan massa bangunan menyesuaikan dengan syarat dan kebutuhan masing-masing bangunan yang dapat dilihat pada Gambar 1.

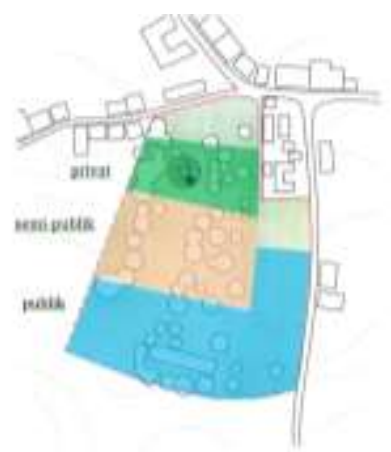

Gambar 1. Pemintakatan Hierarki Ruang

Pada perancangan proyek ini akan menggunakan massa jamak sehingga tiap massa akan memiliki fungsinya masingmasing yang dapat dilihat pada Gambar 2 .

Untuk gubahan massa bangunan didapat dari konsep metafisika yang sudah dijabarkan. Secara fisik bentuk bangunan digubah dari beberapa elemen yang ada di alam sehingga bentuk yang akan muncul dapat lebih dinamis dan menyatu dengan alam seperti yang ditunjukkan pada Gambar 3, 4, dan 5.
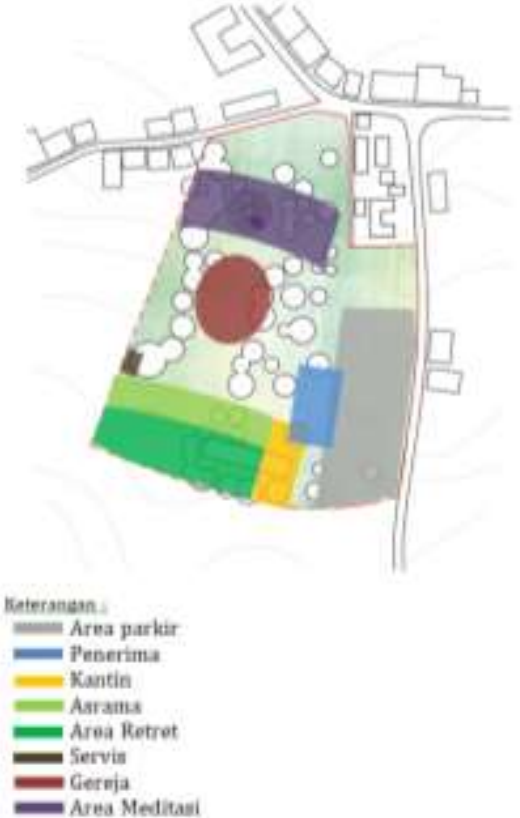

Gambar 2. Pemintakatan Mikro Ruang

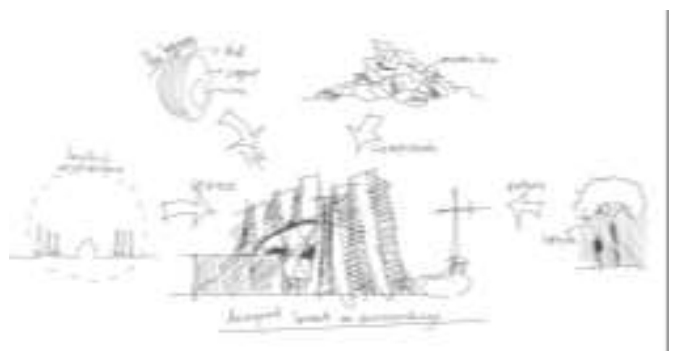

Gambar 3. Ide Gubahan Massa

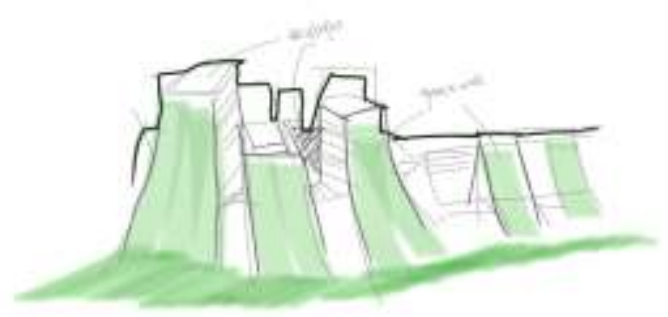

Gambar 4. Ide Gubahan Massa Gereja

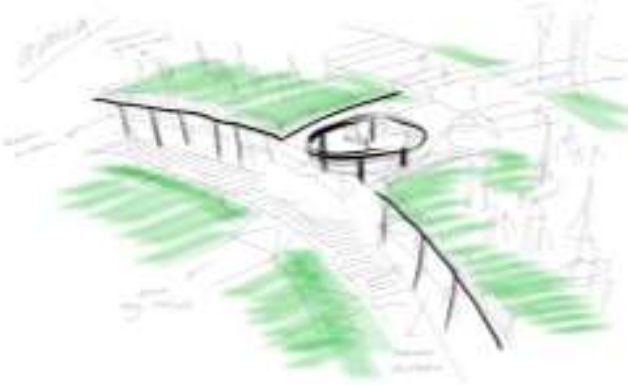

Gambar 5. Ide Gubahan Massa Asrama

Material yang akan diaplikasikan pada proyek adalah material-material yang 
sederhana dan alami, antara lain: kayu, tumbuhan, batu, dan kaca. Material-material ini digunakan karena dapat membentuk atmosfer dan suasana baik di luar maupun dalam ruang.

Nantinya pada tiap fungsi bangunan akan ada akses atau ruang transisi penghubung. Masing-masing ruang transisi pada khususnya gereja dan area asrama haruslah memiliki makna yang dapat dimengerti oleh pengguna.

Terapan pencahayaan alami dalam ruang akan diterapkan skylight karena kondisi lingkungan sekitar Bandungan yang hanya disinari matahari pada jam $11.00-14.00$, sehingga penempatan bukaan lebih didominasi pada atap bangunan.

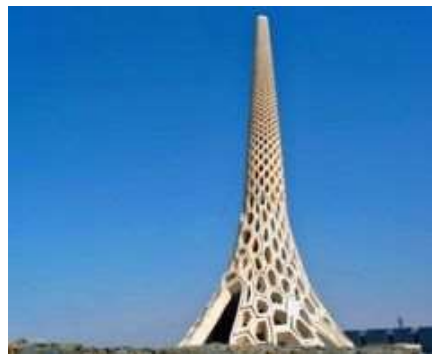

Gambar 6. Gambar Wind Catcher (sumber :

Untuk terapan penghawaan akan menggunakan metode umum yaitu cross circulation, sehingga dapat menjaga kondisi suhu dan kelembaban dalam ruangan. Sedangkan pada area asrama yang rencana akan diletakkan pada selubung tanah maka penghawaan ruang dalam akan menggunakan metode wind catcher yang berupa sebuah menara di atas bangunan yang dapat mendistribusikan udara dari luar ruangan seperti contoh pada Gambar 5.

\section{KESIMPULAN (KONSEP DESAIN)}

Konsep rancangan Gereja Universal dan Fasilitas Retret mengacu pada proses mengembalikan hakikat manusia dan hubungannya dengan Tuhan. Kehidupan yang semakin modern, maka membuat manusia lupa akan keberadaannya di dunia karena Tuhan. Maka dari itu, pendekatan Metafisika digunakan. Dengan menggunakan kekuatan alam sebagai ciptaan Tuhan yang pada akhirnya akan membuat manusia secara tidak sadar mengagumi dan kembali mengingat Tuhan bukan hanya karena formalitas, namun juga karena kesadaran diri sendiri.

Nama : Gereja Universal dan Retret

Lokasi : Bandungan, Semarang, Jawa

Tengah

Luas Lahan $\quad: 25.000 \mathrm{~m}^{2}$

Kegiatan : Beribadah, Retret dan Rekreasi

Penerapan hierarki fungsi dapat dilihat pada Lampiran. Penggunaan elevasi tanah untuk membedakan persyaratan masingmasing area. Untuk area publik ruangan yang ada antara lain : area parkir, penerima, kantin, area asrama, area retret, dan komunal. Area semi publik adalah area gereja karena di dalamnya menampung kegiatan ibadah yang masih ada bentuk komunikasi antar penguna. Area privat adalah area untuk bermeditasi yang berada di dataran yang paling tinggi.

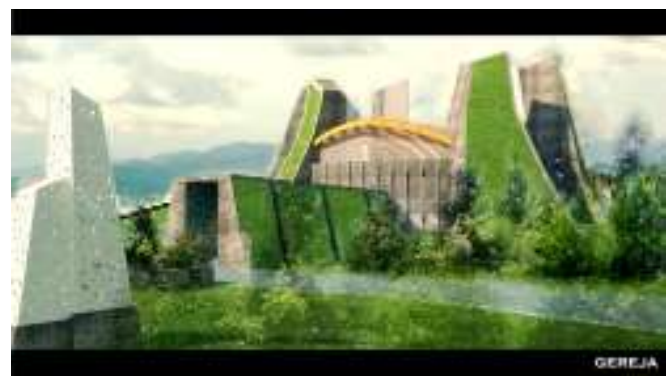

Gambar 7. Gereja

Bentuk massa utama gereja dan asrama retret dibentuk dari archetype atau pola-pola dasar yang diambil dari alam yang kemudian diolah sedemikian rupa agar bentuknya dinamis dan menyatu dengan alam yang dapat dilihat pada Gambar 7 dan Gambar 8.

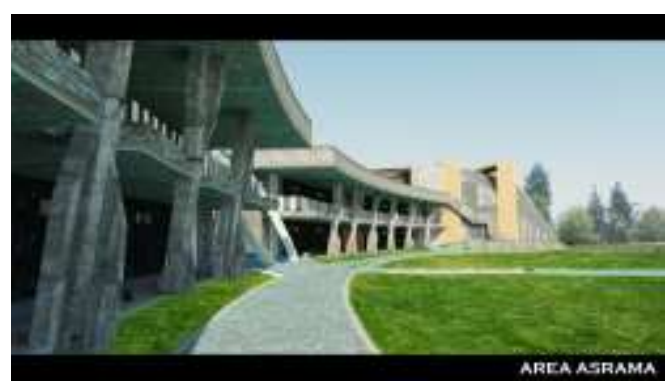

Gambar 8. Area asrama

Penciptaan atmosfer dan suasana yang sakral pada ruang dalam gereja dan aula dengan cara menerapan skylight agar dapat mendistribusikan cahaya alami ke dalam ruang 
yang dapat dilihat pada Gambar 9 dan Gambar

10.

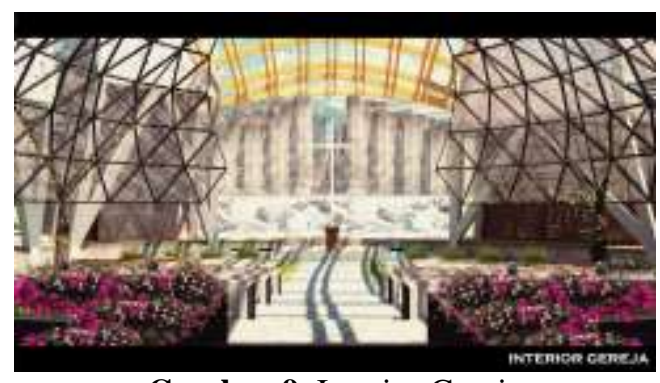

Gambar 9. Interior Gereja

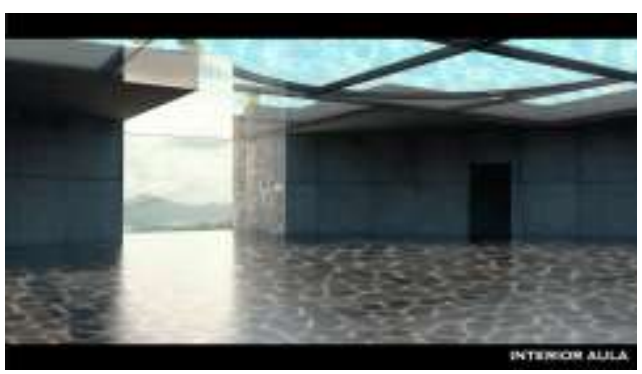

Gambar 10. Interior Aula

\section{REFERENSI}

Lynda S. Waggoner, 1996, Fallingwater:

Frank Lloyd Wright's Romance With

Nature, Pennsylvania : Universe

Publishing

Mangunwijaya, Y.B, 1988, Wastu Citra, Jakarta : Gramedia

Zumthor, Peter, 1999, Thinking Architecture, Basel; Boston; Berlin : Birkhäuser 


\section{LAMPIRAN}

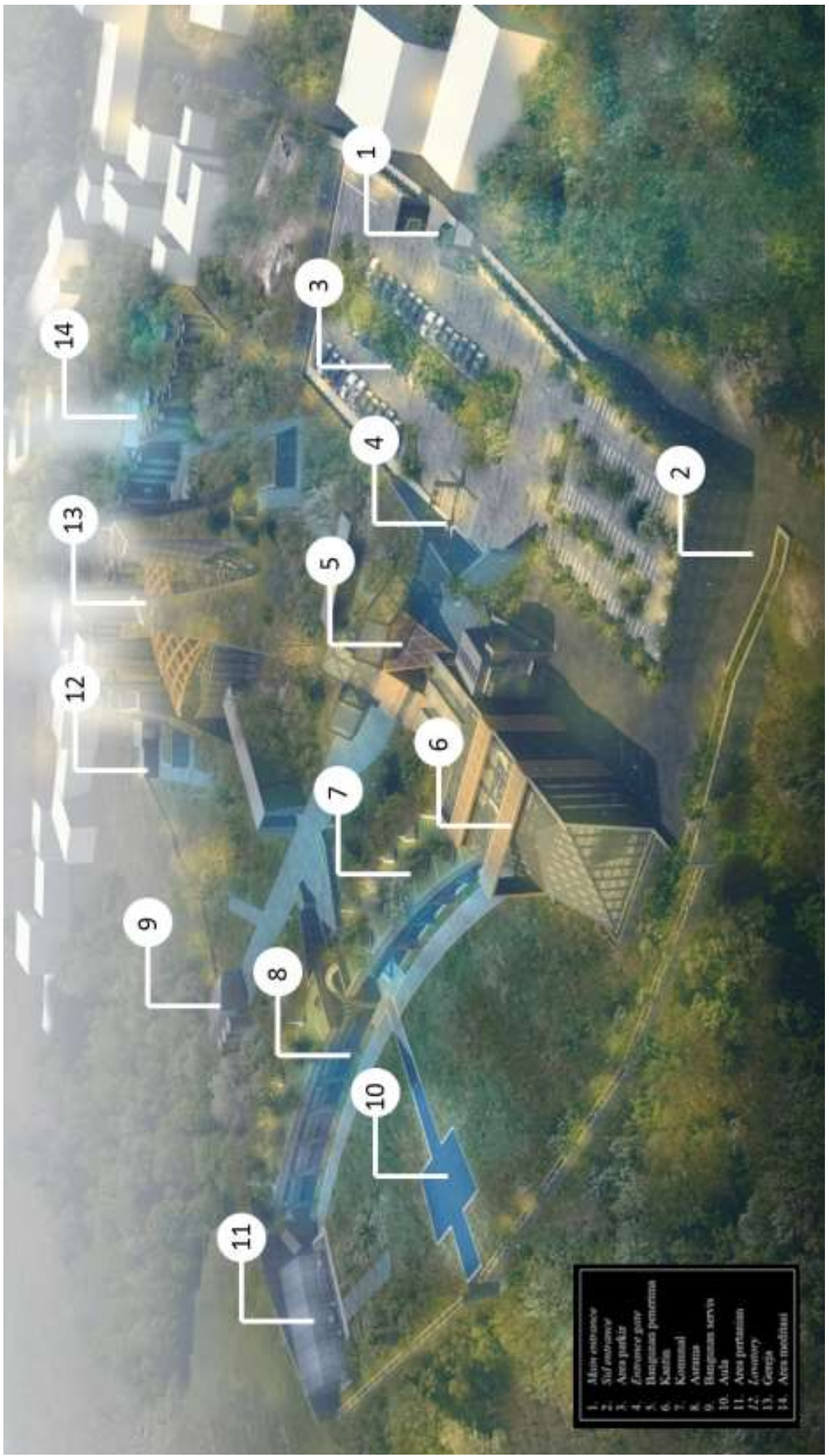

